\title{
DISTRIBUIÇÃo dOS DIÂMETROS NUMA FAIXA DE CERRADO NA FAZENDA ÁGUA LIMPA (FAL) EM BRASÍLIA-DF
}

\author{
J.M. Felfili ${ }^{1}$ \\ M.C. da Silva Júnior ${ }^{1}$
}

Recebido em 20-2-88. Aceito em 3-10-88.

\begin{abstract}
RESUMO - Com os dados de 21 parcelas permanentes de $1.000 \mathrm{~m}^{2}(20 \times 50 \mathrm{~m})$ alocadas no inventário contínuo de uma faixa de cerrado com 152 ha $(400 \times 3.800 \mathrm{~m})$ na Fazenda Água Limpa (FAL)-DF (15 $56^{\prime} 14^{\prime \prime} \mathrm{S}$ e $\left.47^{\circ} 46^{\prime} 08^{\prime \prime} \mathrm{W}\right)$, foi realizado o estudo da distribuição diamétrica dos indivíduos com mais de $5 \mathrm{~cm}$ de diâmetro a $30 \mathrm{~cm}$ do solo. Foram estudadas também as 17 espécies com maior índice de importância (IVI). Para a população total, $63,85 \%$ dos indivíduos concentram-se na primeira classe de diâmetro $(5-9 \mathrm{~cm})$, fato atribuído ao pequeno porte que geralmente apresentam algumas das espécies do cerrado e/ou à incidência de incêndios em intervalos que, na maioria das vezes, não ultrapassam três anos.
\end{abstract}

Palavras-chave: Distribuição, diâmetros, cerrado.

ABSTRACT - This paper studied the stem distribution in 152ha of "cerrado" area in the Água Limpa Farm (15 $56^{\prime} 14^{\prime \prime}$ 'S and $\left.47^{\circ} 46^{\prime} 08^{\prime \prime} W\right)$, Brasilia-DF, Brazil. Sampling was done only on individuals with, at least, $5 \mathrm{~cm}$ of stem diameter, $30 \mathrm{~cm}$ above ground. It was sampled 21 permanent plots, $1,000 \mathrm{~m}^{2}(20 \times 50 \mathrm{~m})$ each, randomly allocated. The 17 species with the highest importance value (IVI) was studied too. The Liocourt "q" quocients were calculated to permit distribution evaluation. For each species studied, the present situation was evaluated and hypothesis were made about the problems affecting the population.

Key words: Distribution, diameters, "cerrado".

\section{Introdução}

O cerrado ocupa parcela considerável do território nacional, aproximadamente 2 milhões de $\mathrm{km}^{2}$ segundo Alvim e Araújo (1952). Assim, é uma das formações importantes no país, ocorrendo em todo o Brasil Central, partes da Amazônia, do Nordeste e do Sudeste. Entretanto, há uma grande carência de dados sobre a estrutura e o comportamento das espécies do cerrado. Apenas com estudos detalhados será possível a prática de intervenções com objetivos econômicos e a apli-

\footnotetext{
${ }^{1}$ Departamento de Engenharia Florestal, Caixa Postal 152807, Universidade de Brasília - 70910 Campus Universitário - Brasília-DF
} 
cação de métodos de manejo adequados, de modo a preservar as características dessa vegetação.

O primeiro trabalho sobre ecologia do cerrado foi realizado por Warming (1908), que realizou estudos ets Lagoa Santa-MG, destacando como seus principais condicionadores os fatores físicos do solo, a geologia, as condições topográficas e os fatores climáticos. Desde então, vários autores têm pesquisado o cerrado, procurando explicar os fatores que o determinam, tais como Cole (1960), Goodland (1969), Eiten (1972), Goodland e Pollard (1973), Haridasan (1982), Medeiros (1983), Ribeiro (1983), Araújo (1984), Felfili e Silva Júnior (1986). Mesmo assim ainda há muito que se descobrir a respeito do comportamento do cerrado como um todo e de cada espécie individualmente.

Nos ambientes tropicais é muito difícil a avaliação das idades dos indivíduos, uma vez que os anéis de crescimento ou não se apresentam bem formados ou ocorrem sem que seja possível correlacioná-los com alguma variação climática anual, como ocorre nos sistemas temperados (Daubenmire, 1968).

Embora sejam grandes as dificuldades, Moraes (1970) constatou surtos de crescimento para todos os indivíduos de uma população, quando analisou 21 espécies florestais da Amazônia, indicando que indivíduos com diâmetros maiores devem ser considerados mais velhos para uma mesma espécie. Assim, a medição dos diâmetros pode ser usada como uma forma de avaliação das idades (Daubenmire, 1968; Harper, 1977).

A avaliação da distribuição dos diâmetros, mesmo que apresente problemas para a avaliação das idades, fornece a estrutura de tamanho das populações, de grande importância para predições sobre a produção florestal. Neste sentido, a idade real das árvores não é um parâmetro muito importante (Harper, 1977).

A comunidade $\mathrm{e}$ as populações que a compõem são sensíveis às condições do ambiente (Daubenmire, 1968); desta forma, a disposição dos dados em histogramas de freqüência nas classes de diâmetro retratam a situação atual, podendo-se ainda supor perturbações ocorridas como: incêndios, desmatamentos, baixos índices de polinização ou germinação, ataque de pragas e doenças. Estas se apresentam como interrupções nos histogramas, indicando que o ciclo de vida das espécìes não estaria completando-se.

Assim, o objetivo deste estudo é estabelecer a situação atual da distribuição diamétrica da vegetação e de algumas das espécies do cerrado da FAL, visando a reconhecer problemas e a comparar com distribuições de outras áreas para indicar estratégias de ação que minimizem as perturbações na comunidade.

\section{Material e métodos}

O trabalho foi desenvolvido na Fazenda Água Limpa (FAL), de propriedade da Universidade de Brasília, no Distrito Federal, com altitude de $1.100 \mathrm{~m}$ e situada a $15^{\circ} 56^{\prime} 14^{\prime}$ 'S e $47^{\circ} 46^{\prime} 08^{\prime \prime} ' W$ de GW, onde, conforme dados da Estação Meteorológica da FAL, a pluviosidade média anual é de $1.600 \mathrm{~mm}$, com maior intensidade 
no período novembro-janeiro e estiagem quase total de junho a setembro, as temperaturas médias mínimas são aproximadamente de $28,5^{\circ} \mathrm{C}$ em setembro e de $12^{\circ} \mathrm{C}$ em julho.

Foi estudada uma faixa de cerrado s.s. com 152 ha $(400 \times 3.800 \mathrm{~m})$ onde foram instaladas 21 parcelas permanentes de $1.000 \mathrm{~m}^{2}(20 \times 50 \mathrm{~m})$. Nessas parcelas foram mensurados os Dbs (diâmetros na base do tronco) de todas as árvores encontradas com mais de $5 \mathrm{~cm}$ de diâmetro, tendo sido mensuradas 2.014 árvores. A análise fitossociológica da área (Felfili e Silva Júnior, 1986) apresentou 61 espécies, tendo sido selecionadas as 17 com maior índice de valor de importância (IVI) (Tabela 1), que foi calculado segundo Mueller Dumbois \& Ellemberg (1974) e Martins (1979), como se segue:

a) Abundância (A):

A absoluta $=\mathrm{n} / \mathrm{ha}$

$\mathrm{A}$ relativa $=\underline{\mathrm{n} / \mathrm{ha}} \times 100 \%$

(AR) $\quad \mathrm{N} / \mathrm{ha}$

onde:

$\mathrm{n}=$ número de árvores por espécie

$\mathrm{N}=$ número total de árvores

b ) Dominância (D):

D absoluta $=\mathrm{g} / \mathrm{ha}$

$\mathrm{D}$ relativa $=\mathrm{g} / \mathrm{ha} \times 100 \%$

(DR) $\mathrm{G} / \mathrm{ha}$

onde:

$\mathrm{g} / \mathrm{ha}=$ área basal de cada espécie por ha

$\mathrm{G} / \mathrm{ha}=$ área basai total

$\mathrm{g}=\frac{\pi}{4} \mathrm{Db}^{2}$

c) Freqüência $(\mathrm{F})$ :

$\mathrm{F}$ absoluta $=\%$ de parcelas em que ocorre uma espécie

$\mathrm{F}$ relativa $=\Sigma(\mathrm{F}$ absoluta da espécie/ $\Sigma \mathrm{F}$ absoluta $) \times 100 \%$

(FR)

d) IVI $=\mathrm{AR}+\mathrm{DR}+\mathrm{FR}$

O critério utilizado para a seleção das espécies foi o de que a última a ser selecionada deveria ter no mínimo um IVI igual a $20 \%$ do IVI total.

Para o total da vegetação e para essas 17 espécies foram calculados os intervalos de classe ideais conforme as fórmulas (Spiegel, 1970): 
a) Intervalo de classe (IC)

$$
\mathrm{IC}=\frac{\mathrm{A}}{\mathrm{nc}}
$$

onde:

$$
\begin{aligned}
& \mathrm{A}=\text { Amplitude } \\
& \mathrm{nc}=\mathrm{n} \text {. de classes }
\end{aligned}
$$

b)Amplitude (A)

A = Maior diâmetro - Menor diâmetro

c) Número de classes (nc)

$\mathrm{nc}=1+3,3 \log \mathrm{n}$

onde:

$$
\mathrm{n}=\mathrm{n} \text {. de dados }
$$

Os histogramas de freqüência das classes de diâmetro foram construídos seguindo-se o procedimento proposto por Spiegel (1976).

Para a avaliação da distribuição dos diâmetros calculou-se o quociente "q", sugerido por Liocourt (1898) apud Meyer (1952), obtido pela divisão do número de indivíduos de uma classe pelo número de indivíduos da classe anterior. $\mathrm{O}$ autor considera balanceada uma situação em que a redução do número de indivíduos de uma classe para a seguinte ocorreu numa razão constante (quociente “q"). Já numa situação não balanceada, a redução seria diretamente proporcional ao aumento dos diâmetros (Leak, 1964).

$\mathrm{O}$ valor de " $\mathrm{q}$ " representa os indivíduos recrutados e o cálculo 1 - q indica mortalidade entre as classes sucessivas.

\section{Resultados e discussão}

Na Tabela 2 constam as freqüências por classe de $\mathrm{Db}$ por hectare para a totalidade das espécies do cerrado, representada graficamente na Fig. 1.

A razão entre a freqüência de uma classe diamétrica para a classe imediatamente inferior varia em torno de $\mathrm{q}=0,4$, conforme a Tabela 1 , a qual expressa a percentagem de indivíduos que são recrutados de uma determinada classe para a imediatamente superior, já descontada a perda por mortalidade (de Liocourt apud Meyer, 1952). Esta razão mais ou menos constante ao longo de toda a distribuição diamétrica demonstra ter o cerrado estrutura irregular equilibrada com uma distribuição tendendo à balanceada. Em florestas nativas, quando a razão é constante, significa que há um equilíbrio entre mortalidade e crescimento, ou seja, há um balanceamento e, quando isto ocorre por longo período, a estrutura torna-se estabilizada ou balanceada, com um número proporcional de árvores em cada classe diamétrica (Osmaston, 1968). O fato de o cerrado não apresentar uma razão absolutamente constante está de acordo com Harper (1977), segundo o qual, na práti- 
Distribuição dos diâmetros numa faixa...

TABELA 2 - Número de árvores por classe de Db $(\mathrm{cm})$ por hectare para o cerrado da FAL

\begin{tabular}{rrrr}
\hline $\begin{array}{c}\text { Classe de Db } \\
(\mathrm{cm})\end{array}$ & $\begin{array}{c}\text { Número de árvores } \\
\text { absoluto } \\
(\mathrm{N} / \mathrm{ha})\end{array}$ & $\begin{array}{c}\text { Razão } \\
\text { (q)lativo } \\
(\%)\end{array}$ \\
\hline $5-9$ & 612,38 & 63,85 & 0,34 \\
$9-13$ & 207,14 & 21,59 & 0,39 \\
$13-17$ & 81,90 & 8,54 & 0,49 \\
$17-21$ & 40,00 & 4,17 & 0,49 \\
$21-25$ & 10,95 & 1,15 & 0,27 \\
$25-29$ & 3,80 & 0,40 & 0,34 \\
$29-33$ & 1,91 & 0,20 & 0,50 \\
$33-41$ & 0,96 & 0,10 & 0,50 \\
\hline TOTAL & 959,04 & 100,00 & \\
\hline
\end{tabular}


ca, a maioria das florestas irregulares não apresenta distribuição balanceada mas converge para isso.

Pela Tabela 2, constata-se que praticamente a totalidade dos indivíduos do cerrado se concentra nas menores classes de diâmetro até $17 \mathrm{~cm}$, notadamente na primeira classe $(5 \mathrm{a} 9 \mathrm{~cm})$, com $63,85 \%$, seguindo-se a segunda $(9$ a $13 \mathrm{~cm})$, com $21,59 \%$, havendo poucos indivíduos nas últimas classes. Isto se deve principalmente ao fato de que a maioria das espécies do cerrado apresenta pequeno porte. Este tipo de estrutura foi também constatado por Silva Júnior (1984) no cerrado de Paraopeba-MG. Coincidentemente, a máxima concentração de indivíduos na Mata do Capetinga na FAL está também em torno de $17 \mathrm{~cm}$ (Cabral e Felfili, 1986). É interessante notar que as duas estruturas, apesar de uma ser mata e a outra cerrado, se assemelham, estando a taxa de sobrevivência da Mata do Capetinga bastante aproximada $(\mathrm{q}=0,57)$.

No caso da FAL, as classes de diâmetro são contínuas, o que demonstra que o ciclo de vida das espécies está-se completando. Não existem registros de desmatamento em grande escala - o que pode ter ocorrido é a retirada de alguns dos maiores indivíduos em um abate seletivo, ou então as espécies que potencialmente podem atingir um maior porte terem sido restringidas pelos incêndios que ocorrem em intervalos máximos em torno de três anos.

As Figs. 2 a 9 mostram as distribuições das oito espécies que apresentam a tendência ao " J" invertido, assim como a distribuição total. De modo geral, estas espécies também podem ser consideradas, com distribuição tendendo ao balanceamento.

A Palicourea rigida apresenta maior concentração dos indivíduos até $7 \mathrm{~cm}$ de $\mathrm{Db}$ e queda brusca do número de indivíduos entre as primeiras classes, o que demonstra haver mortalidade muito acentuada na fase jovem. A razão q é de 0,55 entre a primeira e a segunda classes, varia em torno de 0,35 entre as classes intermediárias e é de 1 na última classe, indicando a irregularidade da distribuição.

A distribuição da Ouratea hexasperma se assemelha à da Palicourea rigida, com a maioria dos indivíduos nas classes até $11 \mathrm{~cm}$ de Db, com cerca de $50 \%$ entre 5 e $7 \mathrm{~cm}$. Os quocientes " $\mathrm{q}$ " apresentam-se para as primeiras classes com uma tendência ao balanceamento. Para as maiores classes de diâmetro, parece haver um número de indivíduos maior do que aquele que seria necessário para a obtenção de uma distribuição balanceada. Entretanto, esta constatação pode ser avaliada de maneira inversa, evidenciando-se, assim, um grande número de indivíduos de pequeno porte, sugerindo que a população apresenta um grande potencial para se recuperar de um provável distúrbio que tenha ocorrido no passado.

Para Didymopanax macrocarpum, com a quase totalidade dos indivíduos atingindo até $11 \mathrm{~cm}$ de $\mathrm{Db}$, dos quais cerca de $70 \%$ na classe de 5 a $8 \mathrm{~cm}$, a razão q $=0,33$ entre as duas primeiras classes e a distribuição totalmente irregular nas seguintes evidenciam o pequeno número de indivíduos nas classes maiores. Esta espécie, embora se apresente com altura superior à média para o cerrado, conta com diâmetros geralmente pequenos; mesmo assim ocorre a floração, a frutifica- 
ção e novos indivíduos se estabelecem, parecendo ser o porte natural da espécie.

A Byrsonima crassa apresenta taxa de mortalidade acentuada nas primeiras classes, razão $\mathrm{q}=0,49$ entre a primeira e a segunda e $\mathrm{q}=0,17$ entre a segunda e a terceira. Após essa queda brusca no número de indivíduos, a razão q passa a 1,00 entre a terceira e a quarta classes, refletindo a constância no número de indivíduos entre essas classes. Em seguida há outra queda $(\mathrm{q}=0,51)$ e volta a haver o mesmo número de indivíduos nas classes subseqüentes (razão $\mathrm{q}=1,0$ ). A quase totalidade dos indivíduos se concentra até $9 \mathrm{~cm}$ de $\mathrm{Db}$, encontrando-se cerca de $60 \%$ na classe de 5 a $7 \mathrm{~cm}$. A distribuição encontrada para esta espécie no cerrado de Paraopeba-MG (Silva Júnior, 1984) é muito semelhante: redução brusca do número de indivíduos da primeira para a segunda classe. No cerrado da FAL, B. crassa floresce e frutifica, indicando ser esta espécie de porte pequeno.

A Aspidosnerma tomentosum também apresenta queda brusca do número de indivíduos entre as duas primeiras classes (razão $\mathrm{q}=0,42$ ), há menos indivíduos na segunda classe do que na terceira $(q=1,1)$, em seguida volta a haver decréscimo $(\mathrm{q}=0,45)$ e ocorre um maior número de indivíduos na última classe do que na penúltima (razão $\mathrm{q}=2,98$ ). Cerca de $80 \%$ do número de indivíduos apresentam $\mathrm{Db}$ até $11 \mathrm{~cm}$; destes, $44 \%$ se encontram na classe de 5 a $7 \mathrm{~cm}$. A incidência nas classes intermediárias de um maior número de indivíduos do que aqueles das classes anteriores indica uma mortalidade excessiva dos indivíduos de menor porte. Torna-se difícil avaliar um evento que incide apenas em indivíduos de dimensões determinadas; assim, o mais provável é que tenha ocorrido algum distúrbio que afetou os indivíduos das classes de $7-9 \mathrm{~cm}$ e $13-15 \mathrm{~cm}$ de diâmetro.

A Sclerolobium paniculatum apresenta taxa de mortalidade menos acentuada entre as primeiras classes do que as espécies anteriores (razão $\mathrm{q}_{1}=0,72, \mathrm{q}_{2}=0,91$ e $\mathrm{q}_{3}=0,84$ respectivamente), nas duas classes subseqüentes essa taxa se acentua (razão $\mathrm{q}_{4}=0,56$ e $\mathrm{q}_{5}=0,44$ ), volta a diminuir na classe seguinte (razão $\mathrm{q}_{6}=$ $0,75)$, na oitava classe há mais indivíduos do que na sétima $\left(\mathrm{q}_{7}=1,33\right)$ e, em seguida, há um decréscimo abrupto na última classe $\left(\mathrm{q}_{8}=0,25\right)$. Cerca de $80 \%$ dos indivíduos se encontram nas classes até $13 \mathrm{~cm}$ de $\mathrm{Db}$. Portanto, parece haver um número excessivo de indivíduos nas classes intermediárias em relação a um número reduzido para as classes de maior diâmetro. Quanto a isso, no cerrado da FAL freqüentemente são encontrados indivíduos de grande porte mortos.

A Qualea parviflora apresenta uma queda acentuada no número de indivíduos entre a primeira e a segunda classes (razão $q_{1}=0,59$ ), em seguida o decréscimo se atenua $\left(\mathrm{q}_{2}=0,92\right.$ e $\mathrm{q}_{3}=0,80$ respectivamente), para voltar a se acentuar nas classes intermediárias e, na última, há igual número de indivíduos do que na penúltima (razão $\mathrm{q}=1,0$ ). Cerca de $76 \%$ dos indivíduos se concentram até $21 \mathrm{~cm}$ de $\mathrm{Db}$, havendo indivíduos que atingem até $41 \mathrm{~cm}$, o que a caracteriza como uma das espécies de maior porte na área estudada. Uma vez que as classes de diâmetro não estão truncadas, admite-se que o ciclo de vida da espécie está-se completando. Sua distribuição apresenta uma concentração de 35,20\% dos indivíduos na menor classe de diâmetro $(5-9 \mathrm{~cm})$. Comparativamente à primeira classe, pode- 
se dizer que as classes intermediárias estão com um número excessivo de indivíduos; entretanto, como os representantes das classes maiores estão em pequeno número, poder-se-ia supor que a população apresenta um bom potencial para futuramente contar com um número adequado de indivíduos de maior porte, tendendo assim para uma condição balanceada. Esta situação poderia sugerir que esta espécie está agora em uma fase de recuperação, devido a algum distúrbio ocorrido anteriormente, que tenha comprometido a densidade da população. A mesma espécie, em um cerrado na EFLEX - Paraopeba (MG) (Silva Júnior, 1984), contou com um número reduzido de indivíduos de maior porte, havendo, entretanto, comprovação de um desmatamento total da área estudada em 1952.

A Kielmeyera speciosa apresenta um decréscimo pouco acentuado da primeira para a segunda classe (razão $\mathrm{q}_{1}=0,92$ ), aumentando nas classes intermediárias (razão $\mathrm{q}_{2}=0,50, \mathrm{q}_{3}=0,45, \mathrm{q}_{4}=0,60$ e $\mathrm{q}_{5}=0,67$ respectivamente), na sétima há um número maior de árvores do que na sexta $\left(\right.$ razão $\left.\mathrm{q}_{6}=1,51\right) \mathrm{e}$, em seguida, há um decréscimo acentuado para a oitava classe $\left(\mathrm{q}_{7}=0,34\right)$. Cerca de $80 \%$ dos indivíduos se encontram nas classes até $8 \mathrm{~cm}$ de $\mathrm{Db}$.

A Qualea grandiflora (Fig. 10) apresenta menor número de indivíduos na primeira classe do que na segunda, o que poderia indicar problemas de regeneração natural (razão $\mathrm{q}_{1}=1,21$ ); em seguida, a distribuição é bastante irregular. Cerca de $70 \%$ do número de árvores se encontram até $11 \mathrm{~cm}$ de $\mathrm{Db}$ e são encontrados indivíduos com até $25 \mathrm{~cm}$. O número de indivíduos de maior porte é reduzido, podendo ser esta uma das causas da pequena representação na primeira classe de diâmetro. A população conta, também, com poucos indivíduos nas classes intermediárias, havendo assim um sério risco de redução da densidade desta espécie na área estudada. Esta distribuição evidencia a possibilidade de abates seletivos, uma vez que, segundo Heiseke (1976), a madeira desta espécie é utilizada regularmente, em forma de tábuas, postes e mobílias.

As espécies Pouteria ramiflora, Miconia pholiana e Dalbergia violacea (Figs. 11 a 13) também apresentam menor número de indivíduos na primeira classe do que na segunda, distribuição irregular nas subseqüentes e se caracterizam pelo acúmulo dos indivíduos nas classes intermediárias; todas apresentam diâmetro máximo em torno de $25 \mathrm{~cm}$. Estas distribuições indicam que o ciclo de vida destas espécies não está completando-se, uma vez que novos indivíduos não estão estabelecendo-se na área. Problemas com polinização, frutificação, predação dos frutos e sementes ou mesmo com a germinação podem ser, provavelmente, os causadores da baixa representação na primeira classe de diâmetro.

A Caryocar brasiliense (Fig. 14) apresenta o mesmo número de indivíduos na primeira e na segunda classes, com acréscimo acentuado desta para a terceira (razão $\mathrm{q}_{2}=2,71$ ). A maior concentração de indivíduos vai desta até a quarta classe, de 11 a $17 \mathrm{~cm}$ aproximadamente, com decréscimo acentuado para a quinta classe (razão $\left.\mathrm{q}_{4}=0,36\right)$ e a seguir continua essa tendência. $O$ diâmetro máximo está em torno de $29 \mathrm{~cm}$. A situação das classes iniciais pode indicar que, em período recente, houve problemas de regeneração natural. 
A Byrsonima verbascifolia (Fig. 15) apresenta menor número de indivíduos na primeira do que na segunda classe (razão $\mathrm{q}_{1}=1,17$ ), o que pode indicar problemas de estabelecimento da regeneração natural em período recente, provavelmente devido à ocorrência de incêndios. A seguir, a tendência continua decrescente, com maior concentração de indivíduos com diâmetros entre 5 e $10 \mathrm{~cm}$ e o máximo em torno de $13 \mathrm{~cm}$. A madeira desta espécie é muito apreciada para lenha caseira, podendo, talvez, ser esta uma das razões do baixo número de indivíduos nas maiores classes. A Roupala montana (Fig. 16) apresenta tendência semelhante: razões $\mathrm{q}_{1}=1,1$ entre a primeira e a segunda classes e $\mathrm{q}_{2}=2,1$ entre esta e a tercei$\mathrm{ra}$, onde se concentra o maior número de indivíduos, diâmetros entre 5 e $9 \mathrm{~cm}$. O decréscimo é abrupto da terceira para a quarta classe (razão $\mathrm{q}_{3}=0,27$ ) e a partir daí a tendência é irregular e decrescente. Os diâmetros máximos também estão em torno de $13 \mathrm{~cm}$; esta distribuição salienta problemas com a regeneração e sugere problemas de redução da densidade desta espécie na área estudada.

A Stryphnodendron adstringens apresenta o mesmo número de indivíduos na primeira e na segunda classes e decréscimo abrupto da segunda para a terceira (razão $q_{2}=0,38$ ), o que pode indicar problemas de regeneração natural com melhora no estabelecimento em período mais recente. Da terceira para a quarta classe há um acréscimo significativo (razão $\mathrm{q}_{3}=1,55$ ) e a partir daí a tendência é decrescente. Os maiores diâmetros atingem até aproximadamente $17 \mathrm{~cm}$. Esta espécie floresce e frutifica abundantemente na área estudada; entretanto, sempre apresenta as sementes brocadas, evidenciando problemas sérios com a predação.

A Pterodon pubescens (Fig. 18) também apresenta tendências semelhantes, com maior concentração de indivíduos entre 13 e $21 \mathrm{~cm}$ e com diâmetros máximos até aproximadamente $33 \mathrm{~cm}$. Faltam indivíduos em uma das maiores classes de diâmetro $(25-29 \mathrm{~cm})$, indicando que houve algum distúrbio na área. Esta espécie, além de ser uma das espécies de maior porte no cerrado, apresenta madeira de excelente qualidade.

\section{Conclusão}

1. O cerrado estudado apresentou distribuição diamétrica tendendo ao " J" invertido, indicando uma estrutura irregular equilibrada com tendência à distribuição balanceada.

2. Das 17 principais espécies, oito apresentaram tendência ao "J" invertido. As demais apresentaram muita irregularidade, mas, de modo geral, com tendência decrescente para as últimas classes, ou seja, poucos indivíduos com diâmetros mais elevados.

3. A maioria das espécies apresentou maior concentração de indivíduos com diâmetros entre 5 e $9 \mathrm{~cm}$.

4. As espécies que apresentam maiores dimensões são Pterodon pubescens, Dalbergia violacea e Qualea parviflora. 


\section{Agradecimentos}

Ao Newton Rodrigues, funcionário da FAL, pela colaboração nos trabalhos de campo, à equipe da SAU do CPD-UnB pelo auxílio no processamento de dados.

\section{Referências bibliográficas}

ALVIN, P.T. \& ARAÚJO, W. 1952. El suelo: factor ecológico en el desarrolo de la vegetación en el Centro-Oeste del Brasil, Turrialba 2(4): 153-160.

ARAÚJO, G.M. 1984. Comparação do estado nutricional de dois cerradões em solos distrófico e mesotrófico no Planalto Central do Brasil. Brasília - Universidade de Brasília. 130 pp. (Tese MS).

CABRAL, R.M. \& FELFILI, J.M. 1986. Distribuição diamétrica e estratificação vertical na mata do Capetinga-DF. In: $V$ Congresso Florestal Brasileiro, Recife.

COLE, M.M. 1960. Cerrado, Caatinga and Pantanal: The distribution and origin of the savana vegetation of Brazil. Geographical Journal 126: 168-179.

DAUBENMIRE, R. 1968. Plant communities: a textbook of plant synecology. New York, Harper e Row Publishers. 300 pp.

EITEN, G. 1972. The cerrado vegetation of Brazil. The Botanical Review 38: 201-341.

FELFILI, J.M. \& SILVA JÚNIOR, M.C. 1986. Inventário florestal de uma faixa de cerrado (152ha) na Fazenda Água Limpa (FAL)-DF. In: V Congresso Florestal Brasileiro, Recife.

GOODLAND, R. 1969. An ecological study of the cerrado vegetation of South-Central Brazil. Montreal (McGill University), (Tese PhD). 224 pp.

GOODLAND, R. \& POLLARD, R. 1973. The Brazilian cerrado vegetation, a fertility gradient. Journal of Ecology 61(2): 219-224.

HARIDASAN, M. 1982. Aluminium acumulation by some cerrado native species of Central Brasil. Plant and Soil 65: 265-273.

HARPER, J.L. 1977. Population biology of plants. London, Academic Press. 892 pp.

HEISEKE, D.R. 1976. Estudos de tipologias florestais do cerrado na região central de Minas Gerais. Brasília. PNUD/FAO/IBDF/BRA-45. 58 pp. (Série técnica, 7).

LEAK, W.B. 1964. An expression of diameter distribution for unbalanced uneven-aged stand and forest. Forest Science 10: 39-51.

MARTINS, F.R. 1979. O método de quadrantes e a fitossociologia de uma floresta residual no interior do Estado de São Paulo: Parque Estadual de Vassununga. São Paulo, Universidade de São Paulo, 239 pp. (Tese D.S.).

MEDEIROS, R.A. 1983. Comparação do estado nutricional de algumas espécies acumuladoras e não acumuladoras de alumínio nativas do cerrado. Brasília, Universidade de Brasília. 91 pp. (Tese M.S.).

MEYER, H.A. 1952. Structure, growth and drain in balanced uneven-aged forests. Journal of Forest. 50: 85-92.

MORAES, V.H.F. 1970. Periodicidade de crescimento do tronco de árvores da floresta amazônica. Pesquisa Agropecuária Brasileira 5: 315-320.

MUELLER-DOMBOIS \& ELLEMBERG, M. 1974. Aims and methods in vegetation ecology. New York, Wiley and Sons. $547 \mathrm{pp}$.

OSMASTON. 1968. The management of forest. Londres, George Allen and Unwin, 1968, $384 \mathrm{pp}$. 
RIBEIRO, J.F. 1983. Comparação da concentração de nutrientes na vegetação arbórea e nos solos de um cerrado e em cerradão no Distrito Federal, Brasilia. Universidade de Brasília. 87 pp. (Tese M.S.).

SILVA JR., M.C. 1984. Composição florística: estrutura e parâmetros fitossociológicos do cerrado e sua relação com o solo na Estação Florestal de Experimentação de Paraopeba, MG. Viçosa, Universidade Federal de Viçosa. 130 pp. (Tese M.S.).

SPIEGEL, M.P. 1970. Estatística, Teoría y Problemas Resueltos. México, McGraw-Hill, 357 pp.

SPIEGEL, M.R. 1976. Estatística. São Paulo, McGraw-Hill. 580 pp. 
TABELA 1 - Lista das 17 espécies com maior IVI no cerrado (s.s.) da FAL

\begin{tabular}{lr}
\hline Espécie & $\mathrm{IVI}$ \\
\hline Qualea parviflora & 31,54 \\
Ouratea hexasperma & 25,00 \\
Qualea grandiflora & 16,71 \\
Sclerolobium paniculatum var. subvelutinum & 14,91 \\
Caryocar brasiliense & 13,99 \\
Dalbergia violacea & 12,41 \\
Byrsonima crassa & 10,59 \\
Stryphnodendron adstringens & 9,91 \\
Palicourea rigida & 8,68 \\
Kielmeyera speciosa & 8,51 \\
Pouteria ramiflora & 8,05 \\
Miconia pholiana & 8,04 \\
Aspidosperma tomentosum & 7,88 \\
Byrsonima verbascifolia & 7,26 \\
Roupala montana & 6,57 \\
Dydimopanax macrocarpum & 6,41 \\
Pterodon pubescens & 6,31 \\
\hline
\end{tabular}




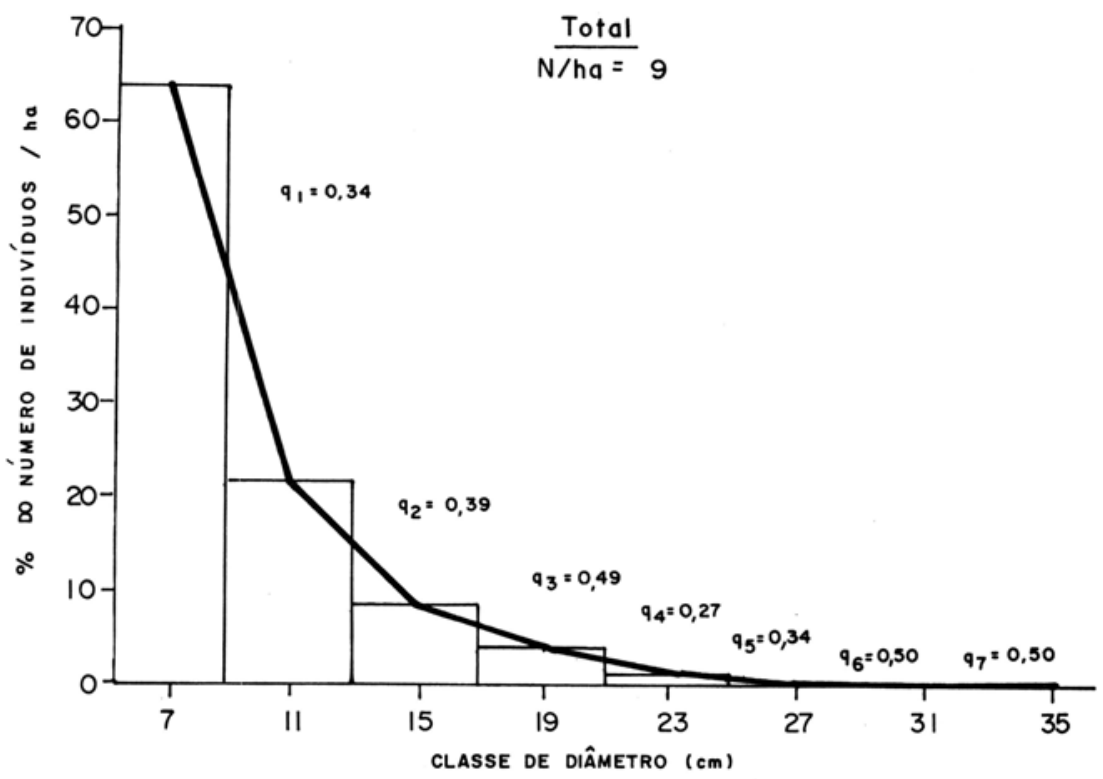

Figura 1 - Número de árvores por classe de $\mathrm{Db}(\mathrm{cm})$ por hectare para o cerrado da FAL.

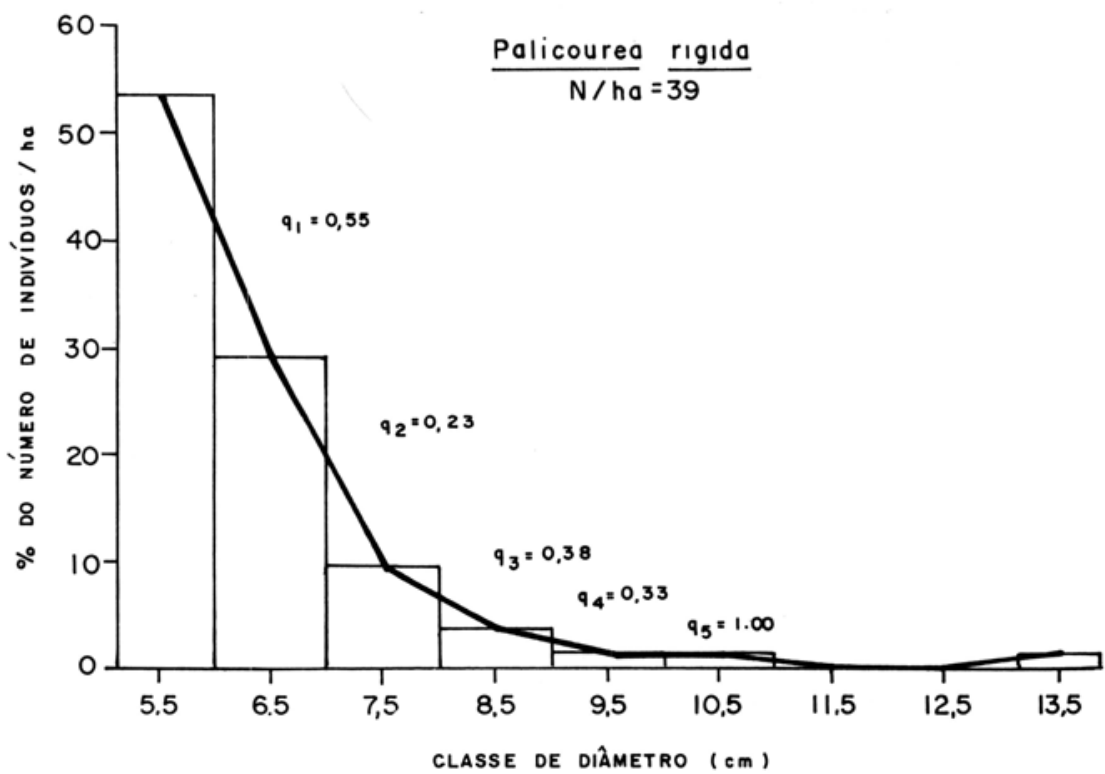

Figura 2 - Número de árvores por classe de $\mathrm{Db}(\mathrm{cm})$ por hectare Palicourea rigida no cerrado da FAL. 


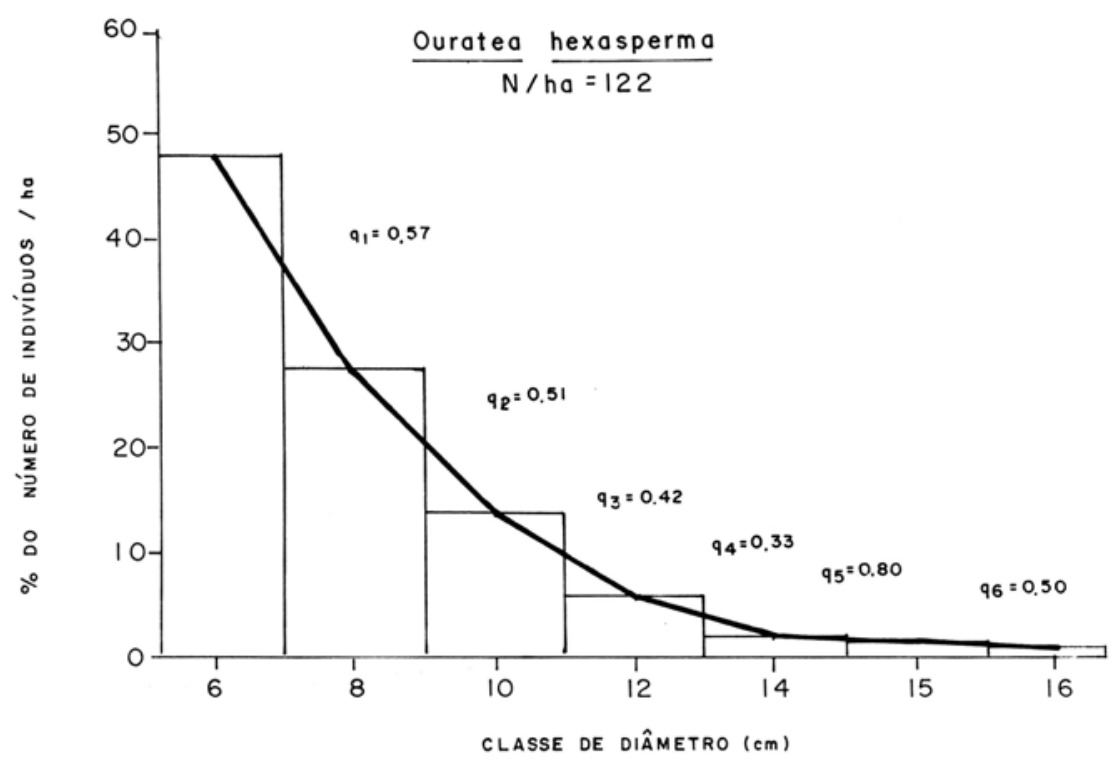

Figura 3 - Número de árvores por classe de $\mathrm{Db}(\mathrm{cm})$ por hectare Ouratea hexasperma no cerrado da FAL.

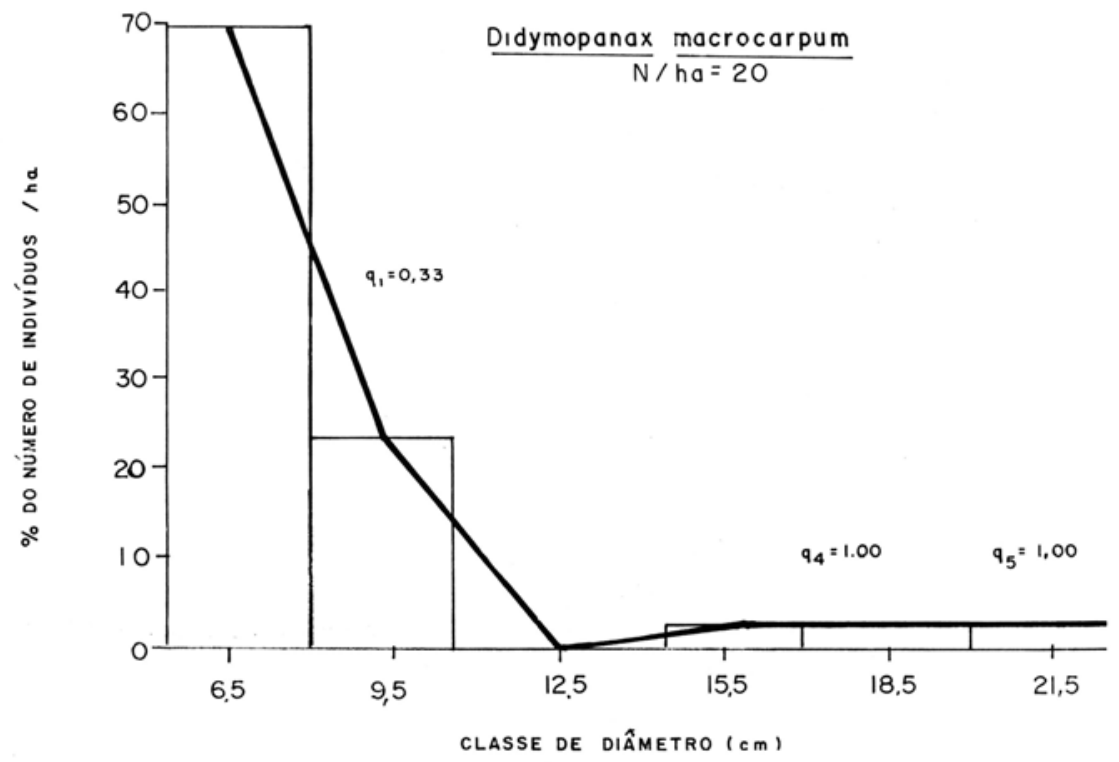

Figura 4 - Número de árvores por classe de $\mathrm{Db}(\mathrm{cm})$ por hectare Didymopanax macrocarpum no cerrado da FAL. 


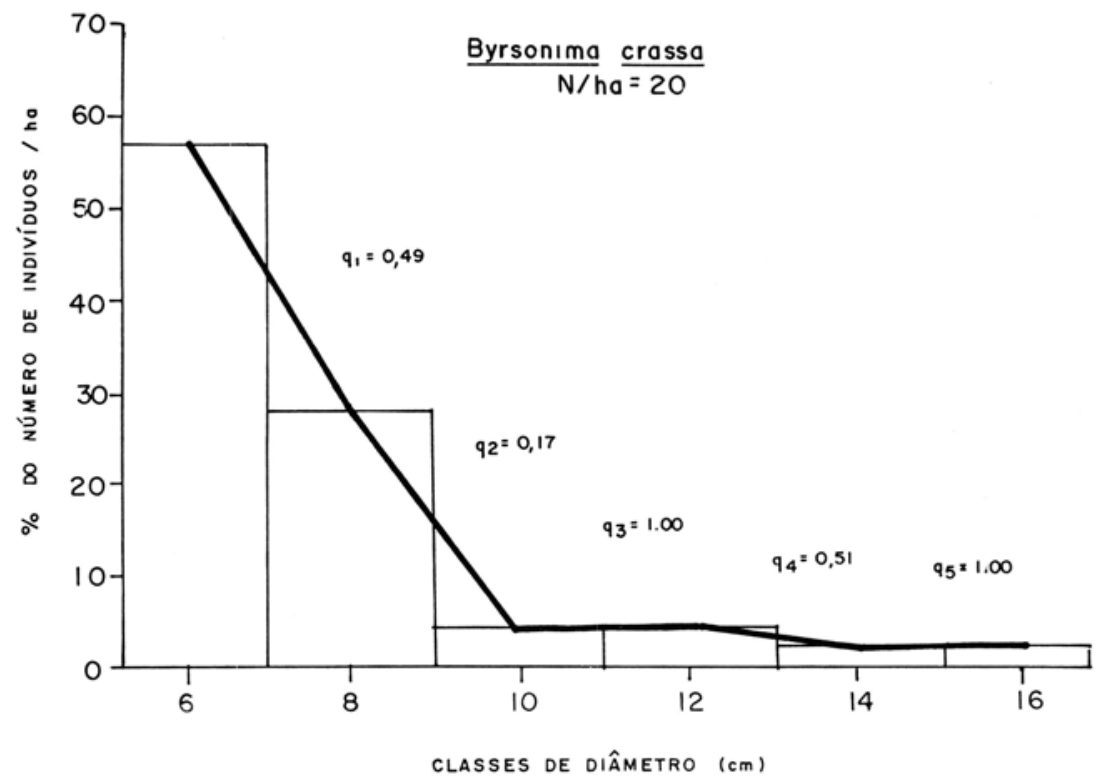

Figura 5 - Numero de árvores por classe de $\mathrm{Db}(\mathrm{cm})$ por hectare Byrsonima crassa no cerrado da FAL.

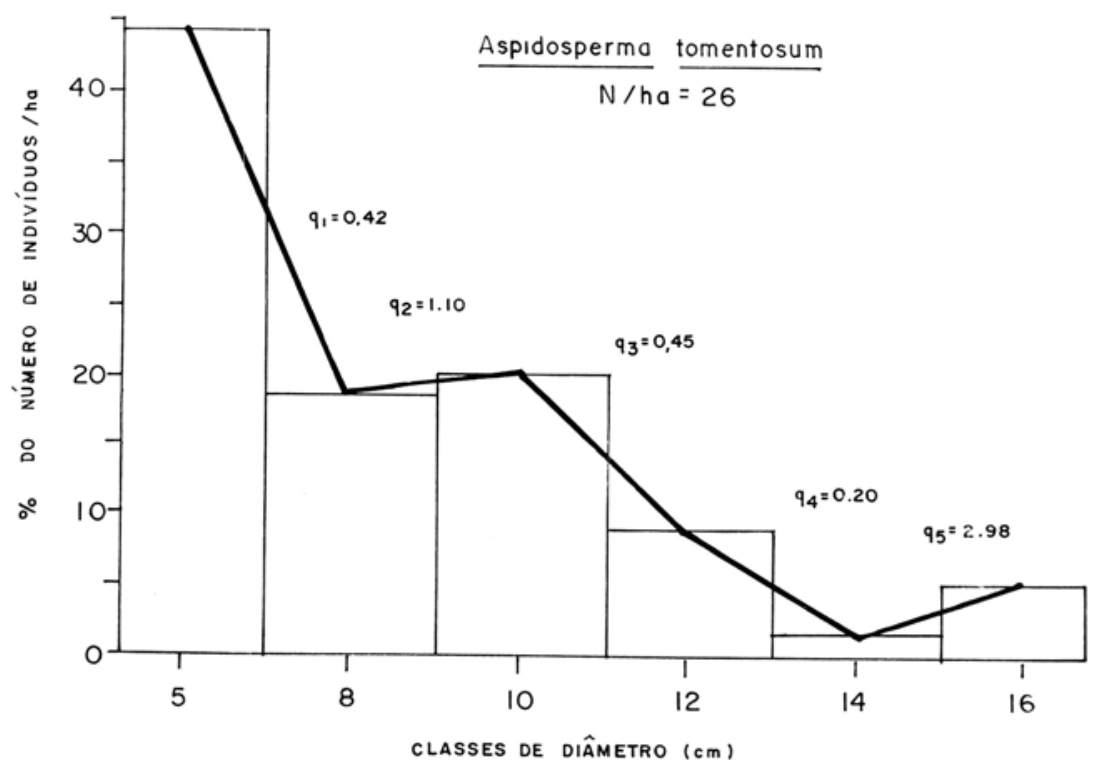

Figura 6 - Número de árvores por classe de $\mathrm{Db}(\mathrm{cm})$ por hectare Aspidosperma tomentosum no cerrado da FAL. 


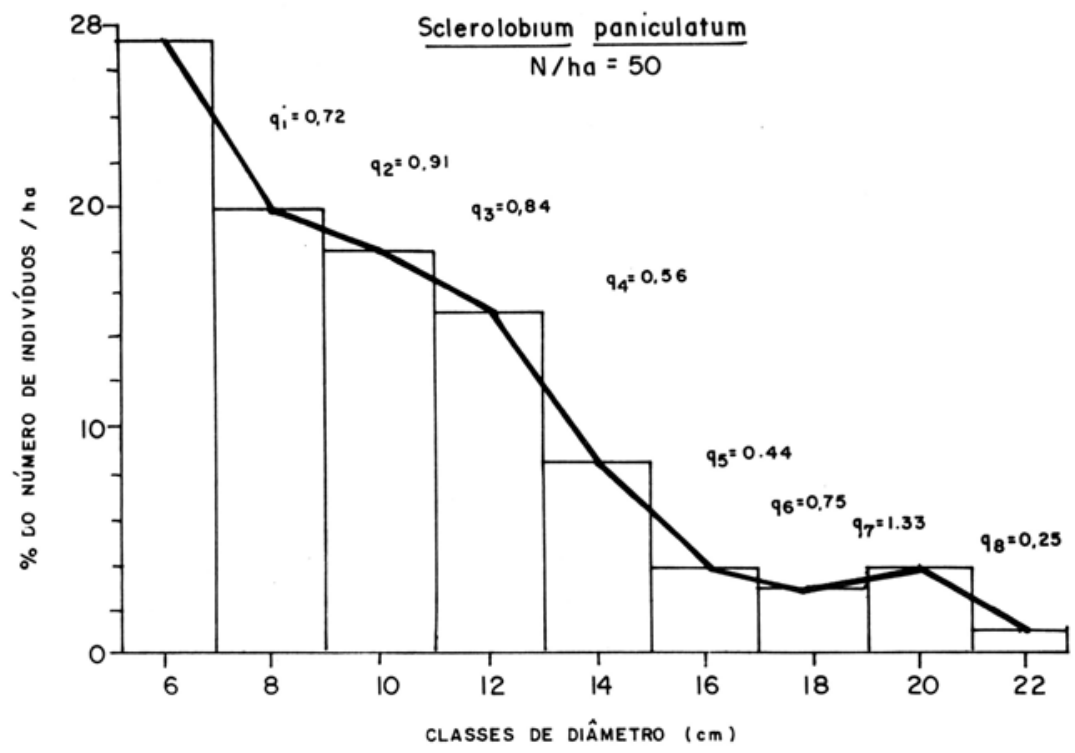

Figura 7 - Número de árvores por classe de $\mathrm{Db}(\mathrm{cm})$ por hectare Sclerolobium painiculatum no cerrado da FAL.

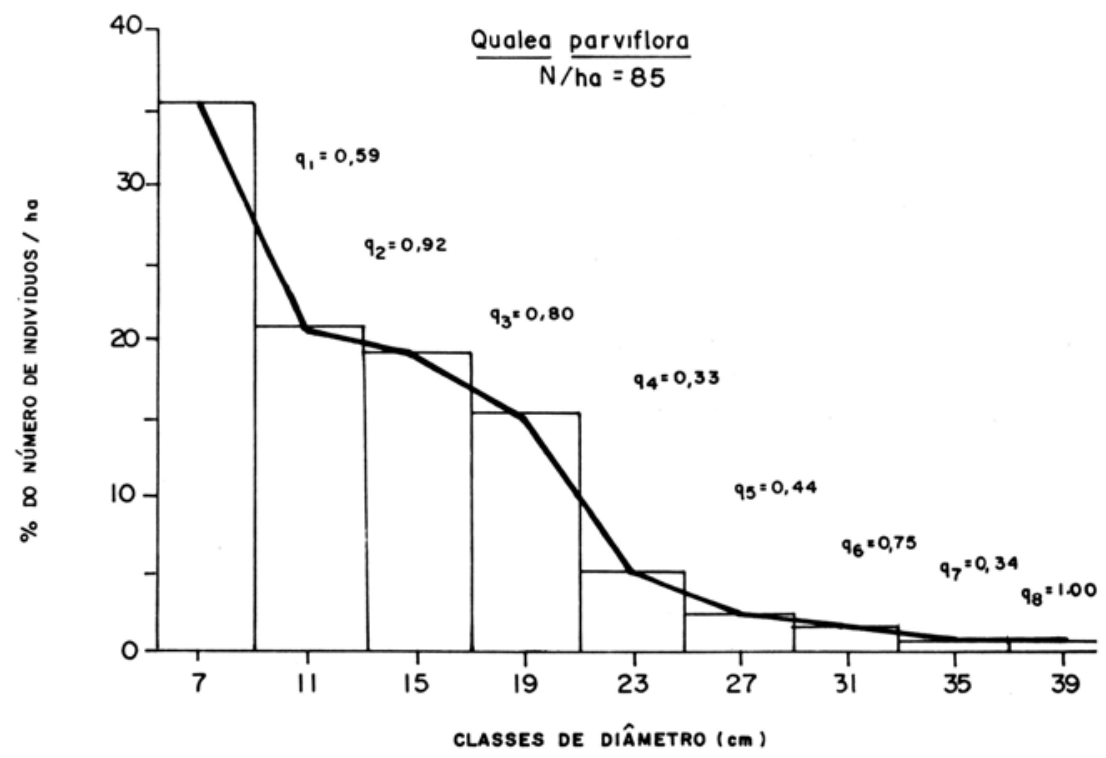

Figura 8 - Número de árvores por classe de $\mathrm{Db}(\mathrm{cm})$ por hectares Qualea parviflora no cerrado da FAL. 


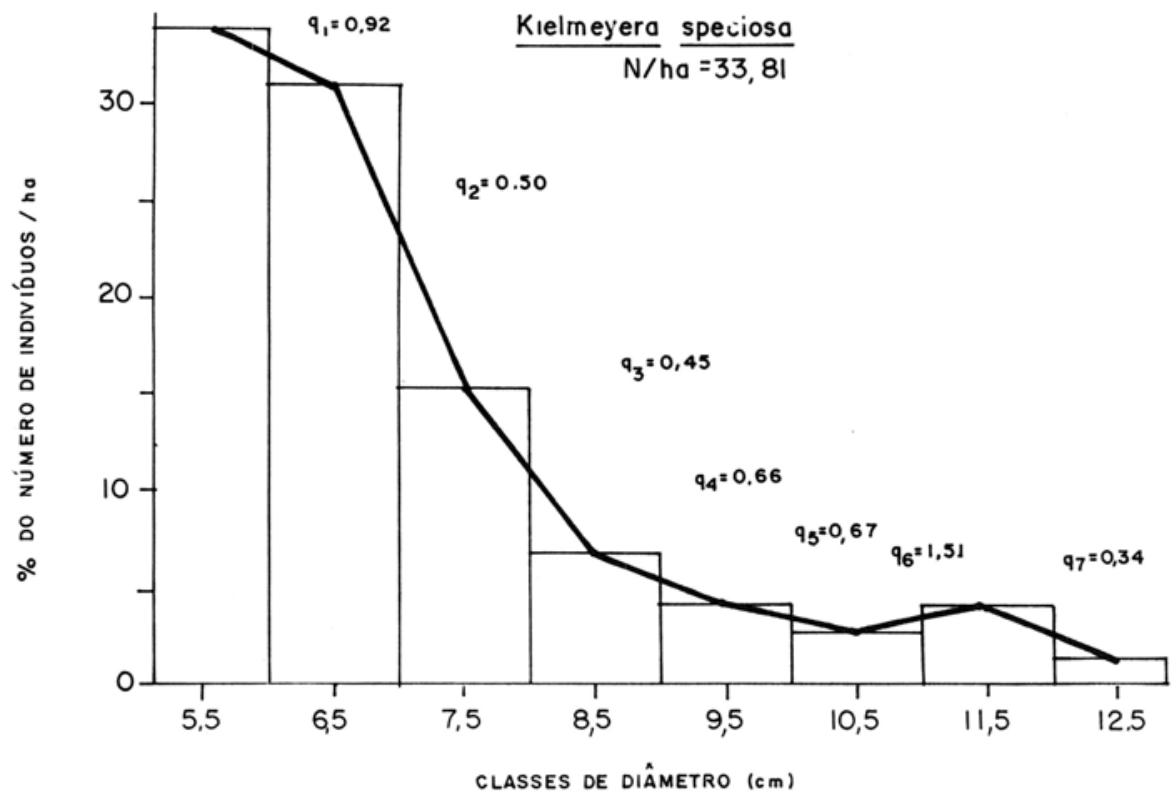

Figura 9 - Número de árvores por classe de $\mathrm{Db}(\mathrm{cm})$ por hectare Kielmeyera speciosa no cerrado da FAL.

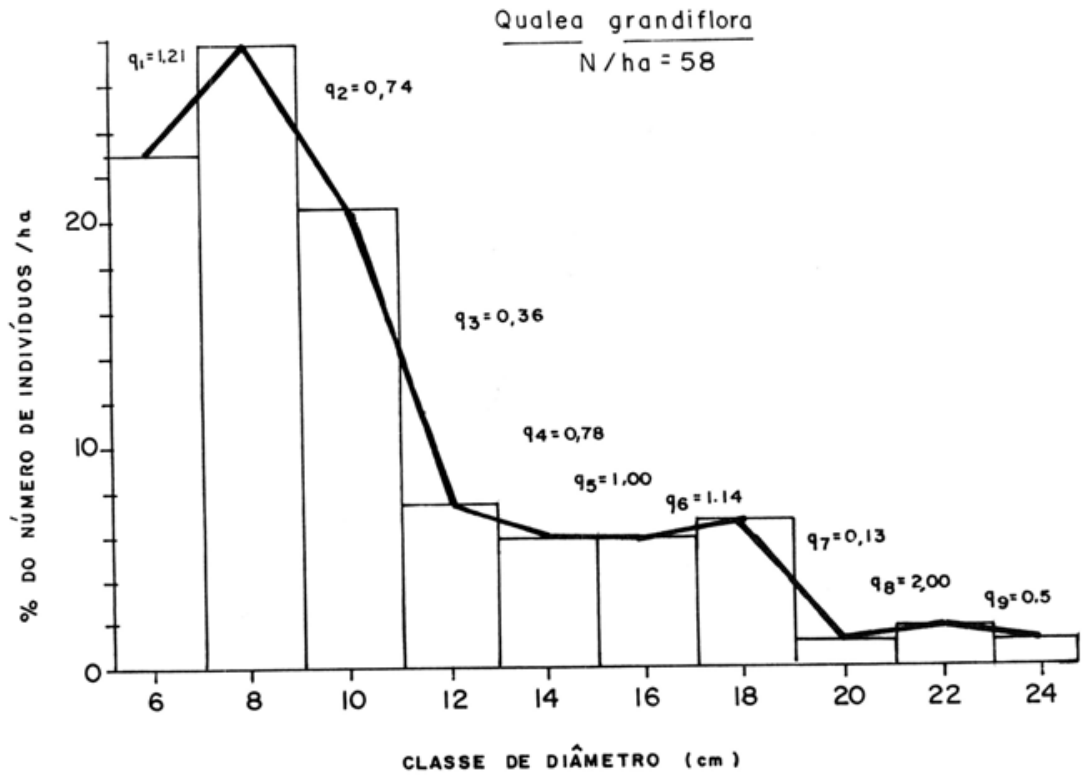

Figura 10 - Número de árvores por classe de $\mathrm{Db}(\mathrm{cm})$ por hectare Qualea grandiflora no cerrado da FAL. 


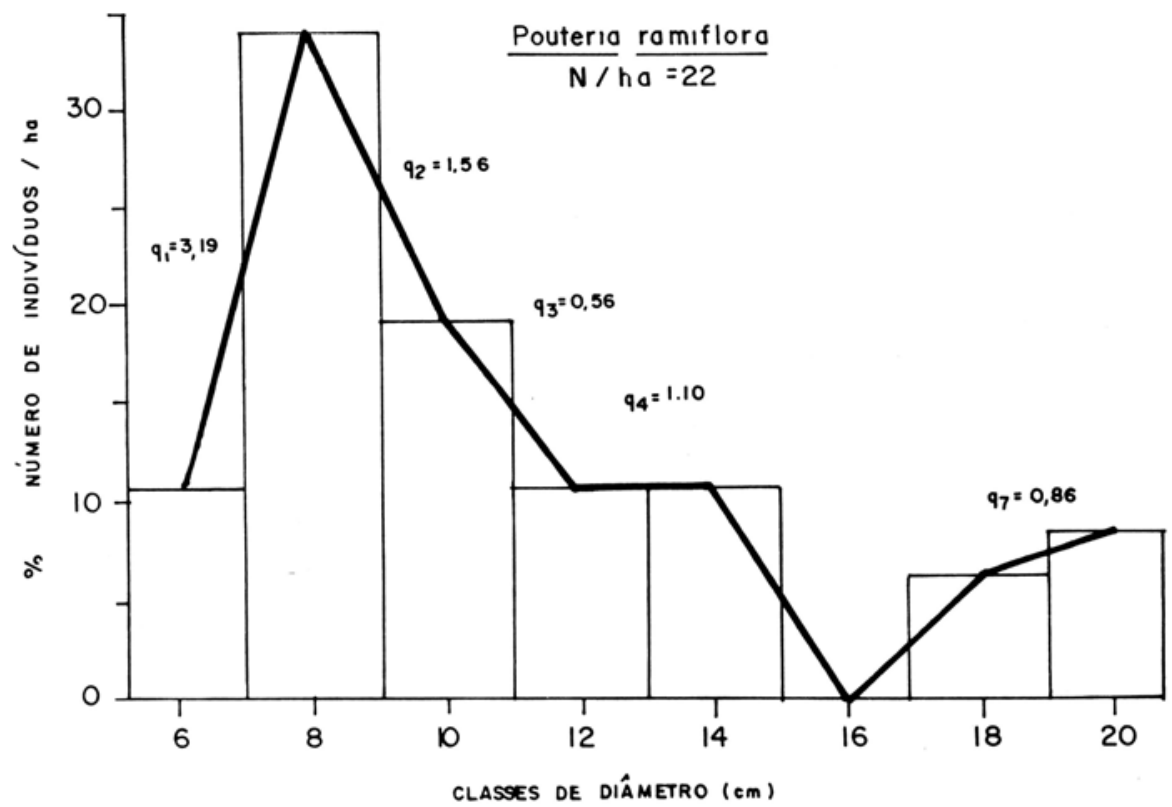

Figura 11 - Número de árvores por classe $\mathrm{Db}(\mathrm{cm})$ por hectare Pouteria ramiflora no cerrado da FAL.

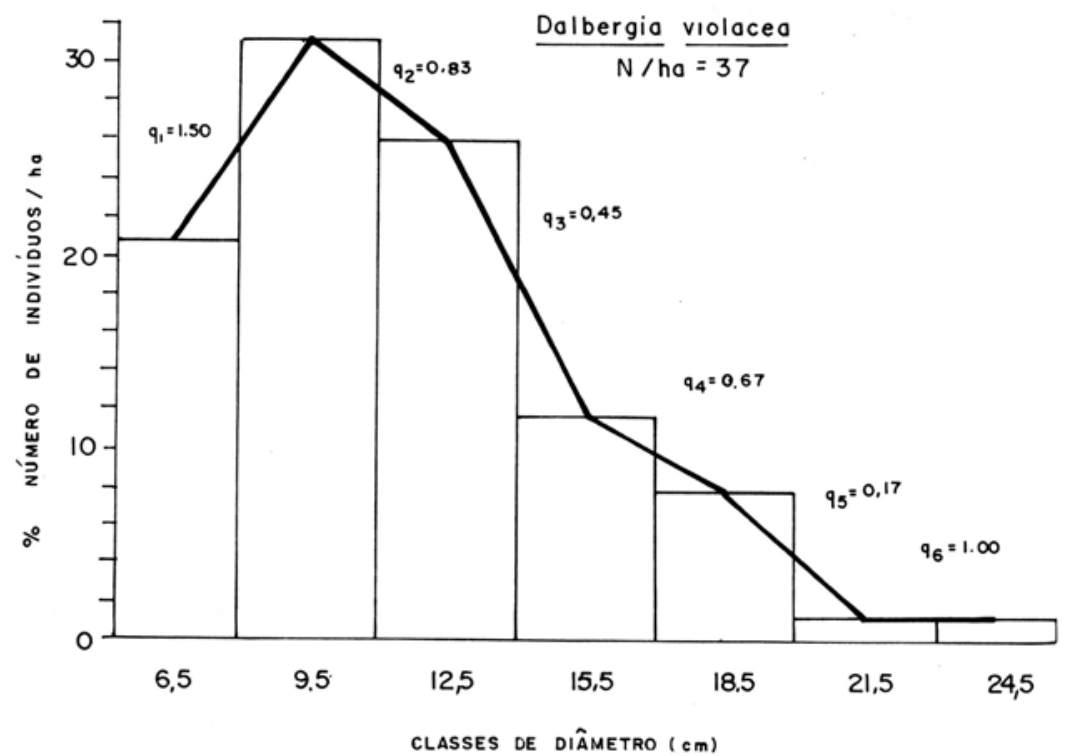

Figura 12 - Número de árvores por classe de $\mathrm{Db}(\mathrm{cm})$ por hectare Dalbergia violacea no cerrado da FAL. 


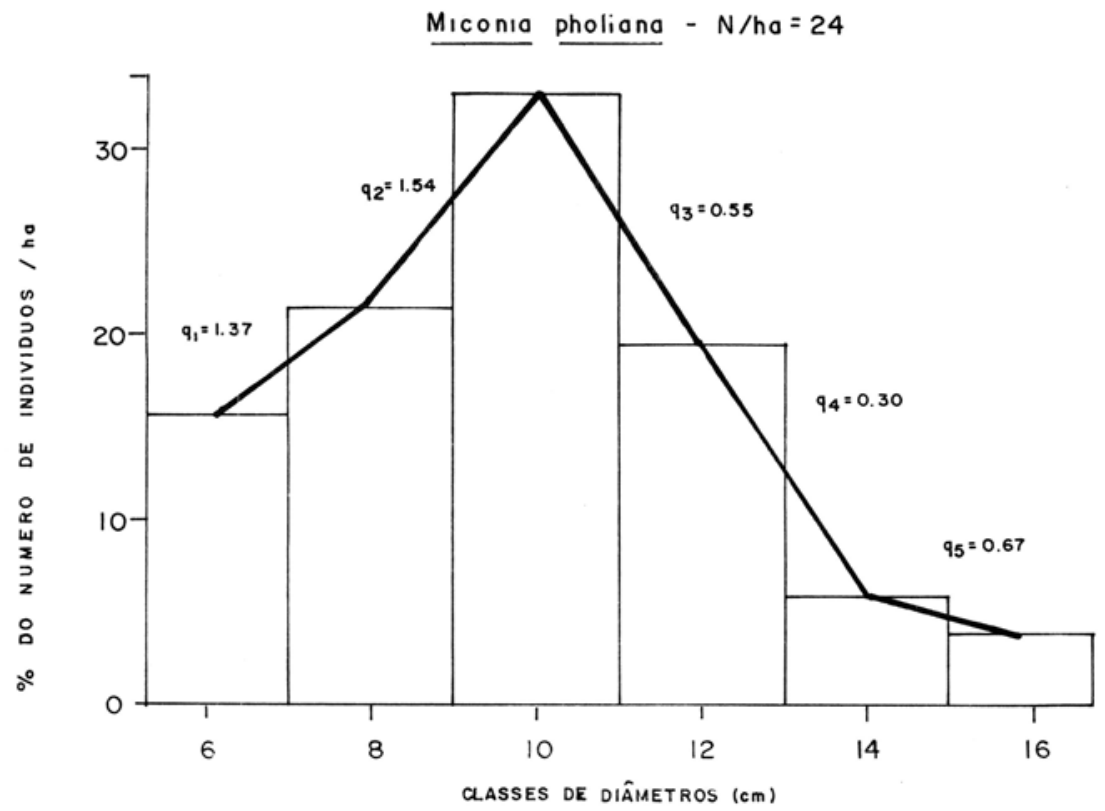

Figura 13 - Número de árvores por classe de $\mathrm{Db}(\mathrm{cm})$ por hectare Miconia pholiana no cerrado da FAL.

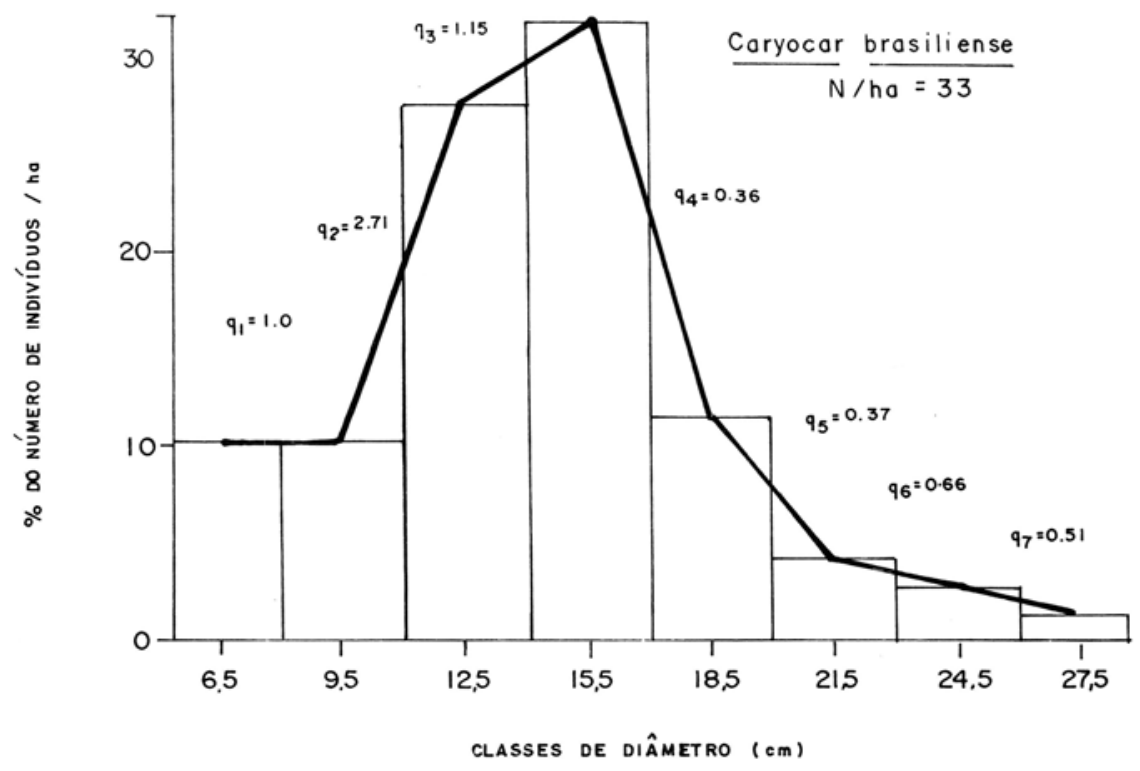

Figura 14 - Número de árvores por classe de $\mathrm{Db}(\mathrm{cm})$ por hectare Caryocar brasiliense no cerrado da FAL. 


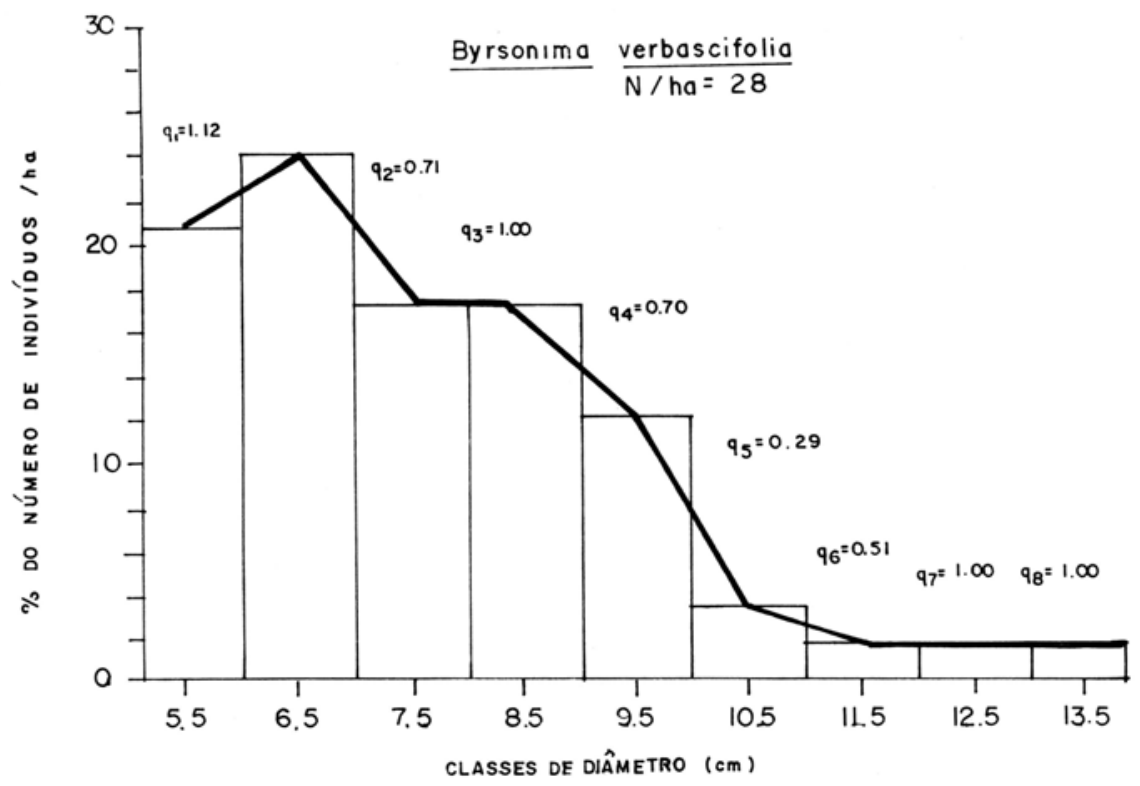

Figura 15 - Número de árvores por classe de $\mathrm{Db}(\mathrm{cm})$ por hectare Byrsonima verbascifolia no cerrado da FAL.

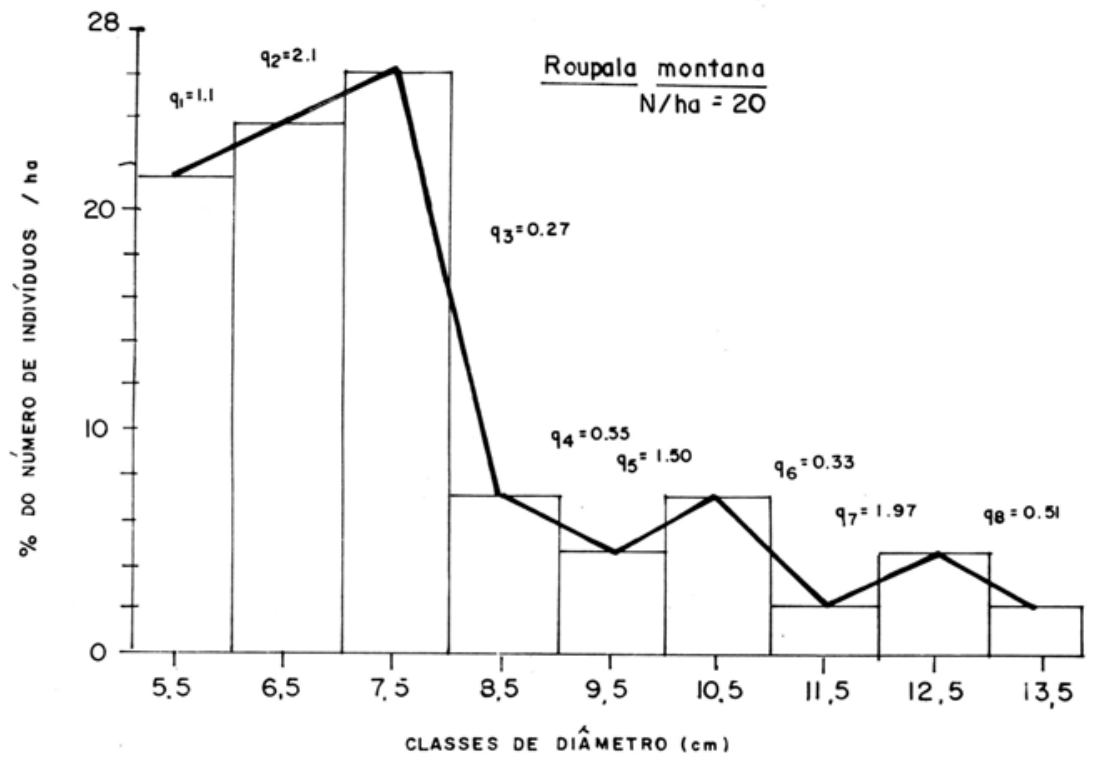

Figura 16 - Número de árvores por classe de $\mathrm{Db}(\mathrm{cm})$ por hectare Roupala montana no cerrado da FAL. 


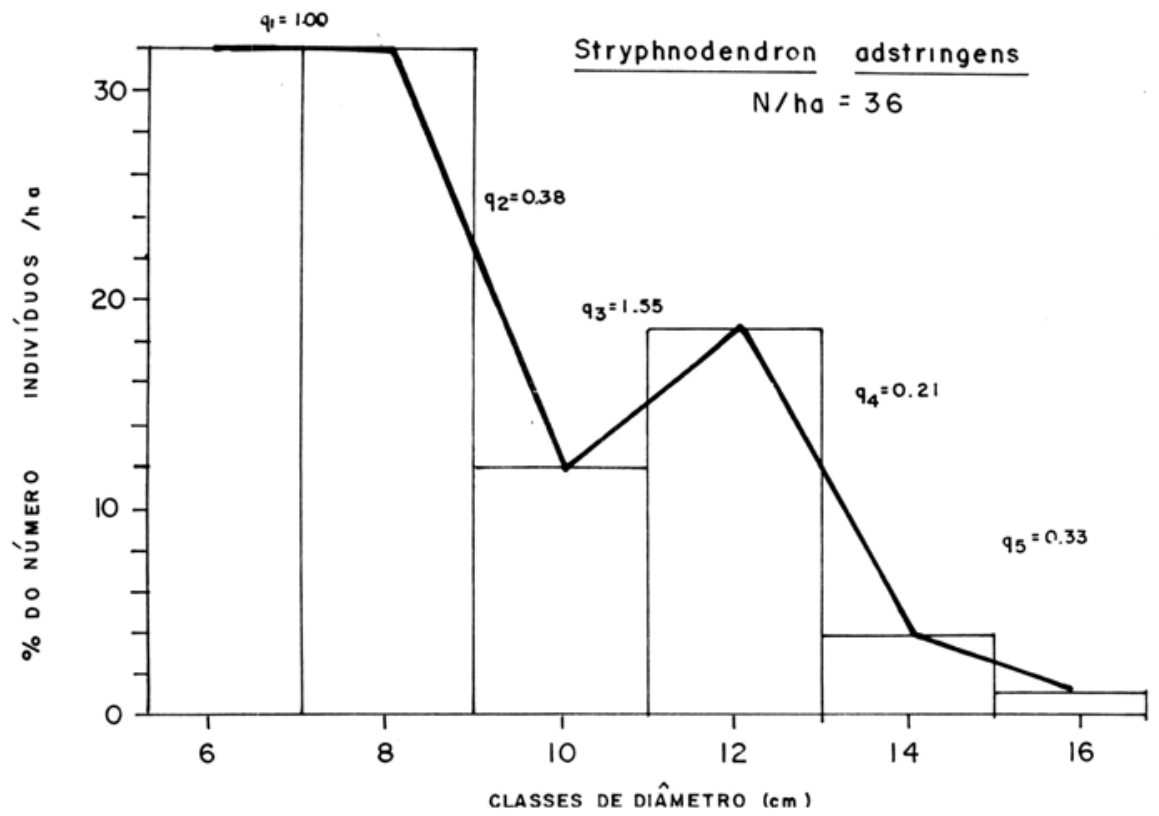

Figura 17 - Número de árvores por classe de $\mathrm{Db}(\mathrm{cm})$ por hectare Stryphnodendron adstringens no cerrado da FAL.

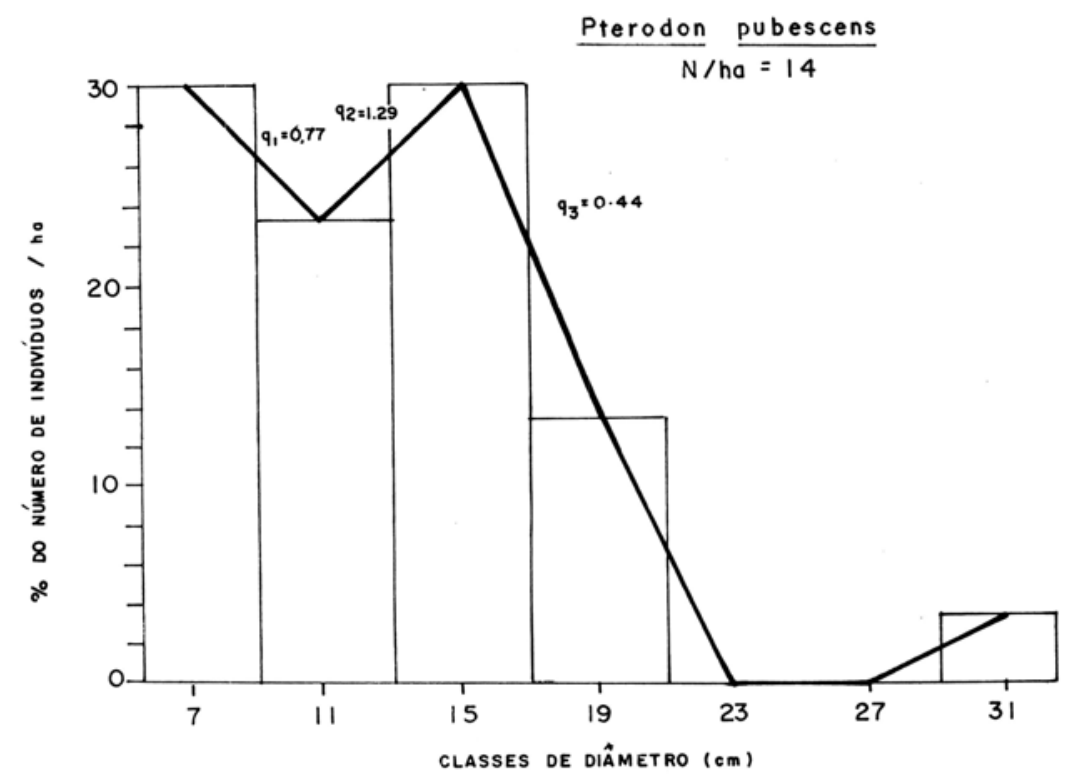

Figura 18 - Número de árvores por classe de $\mathrm{Db}(\mathrm{cm})$ por hectare Pterodon pubescens no cerrado da FAL. 